\title{
Characterization of a Powdery Mildew Resistance Gene in Wheat Breeding Line 10V-2 and Its Application in Marker-Assisted Selection
}

Pengtao Ma, Hongxing Xu, Yunfeng Xu, Liping Song, Shuoshuo Liang, Yuan Sheng, Guohao Han, Xiaotian Zhang, and Diaoguo An, ${ }^{\dagger}$ Center for Agricultural Resources Research, Institute of Genetics and Developmental Biology, Chinese Academy of Sciences, Shijiazhuang 050021, China

\begin{abstract}
Powdery mildew, caused by Blumeria graminis f. sp. tritici, is a serious disease of wheat (Triticum aestivum L.) throughout the world. Host resistance is the most effective and preferred means for managing this disease. Line $10 \mathrm{~V}-2$, a wheat breeding line with superior agronomic performance, shows broad-spectrum seedling resistance to powdery mildew. Genetic analysis demonstrated that its resistance was controlled by a single dominant gene, tentatively designated Pm10V-2. This gene was localized near the documented Pm2 locus on chromosome 5DS using the simple sequence repeat (SSR) marker $C f d 81$. To saturate the marker map of Pm10V-2, more markers were developed using bulked segregant RNA-Seq. Two single-nucleotide polymorphism (SNP) markers (Swgi047 and Swgi064), three expressed sequence tag markers (Swgi007, Swgi029, and Swgi038), and one SSR marker (Swgi066) were polymorphic between the resistant and susceptible bulks and showed tightly linked to the Pm10V-2 gene. Pm10V-2 was flanked by the new developed markers SwgiO64 and SwgiO66 at genetic distances of 0.4 and 1.2 centimorgans (cM), respectively, and cosegregated with Swgi007

and Swgi038. The homologous sequence of Pm2a was cloned from 10V2 based on a recent study. Although the sequence cloned from 10V-2 was completely identical to that of the reported Pm $2 a$-related gene, they did not cosegregate but were separated at a genetic distance of $1.6 \mathrm{cM}$, indicating that $P m 10 V-2$ was different from the reported of Pm2a-related gene. When inoculated with multiple $B$. graminis f. sp. tritici isolates, Pm $10 \mathrm{~V}-2$ had a significantly different resistance spectrum from $P m 2 a$ and other powdery mildew $(\mathrm{Pm})$ resistance genes at or near the $P m 2$ locus. Therefore, $P m 10 V-2$ may be a new Pm2 allele or Pm2-linked gene. To use Pm10V-2 in marker-assisted selection (MAS) breeding, seven markers applicable for MAS were confirmed, including three newly developed markers (Swgi029, Swgi038, and Swgi064) in the present work. Using these markers, a great number of resistant lines with desirable agronomic performance were selected from crosses involving $10 \mathrm{~V}-2$, including the breeding line KM5016, which has been entered in the Regional trials in Hebei Province, China.
\end{abstract}

Wheat (Triticum aestivum L.) powdery mildew is a devastating disease caused by the biotrophic parasitic fungus Blumeria graminis f. sp. tritici. Previous studies indicated that the pathogen of this disease is endemic in almost all wheat-producing regions worldwide, especially in coastal and semicontinental regions (Morgounov et al. 2012; Zhang et al. 2016). For decades, the rapid genetic improvement of wheat cultivars, the increased use of nitrogen fertilizer, and the improvement in irrigation conditions have greatly accelerated wheat production (Bedő and Láng 2015). However, these changes in agriculture have also increased the density of the canopy and humidity levels in the fields (Bedö and Láng 2015). Together with the virulence shift of the pathogen, wheat powdery mildew has been rapidly spreading from cooler and humid areas to warmer and drier regions, including almost all wheat production areas worldwide (Bennett 1984; H. G. Sun et al. 2015; Y. L. Sun et al. 2015).

Since the 1970s, the occurrence of powdery mildew has progressed from a few sporadic wheat fields to most of the winter and spring wheat fields in China (Zhou and Jia 2015). Two severe epidemics were observed in 1990 and 1991, which covered about $40 \%$ of the growing area and led to yield losses of 144 and 77 million tons, respectively ( $\mathrm{Li}$ et al. 2013). In the 21 st century, the epidemics of wheat powdery mildew in China were still severe, causing yield

${ }^{\dagger}$ Corresponding author: D. An; E-mail: dgan@ @jziam.ac.cn

Funding: This research was financially supported by the National Key Research and Development Program of China (number 2016YFD0102002), the National Natural Science Foundation of China (numbers 31501388 and 31771793), the Chinese Academy of Sciences (number XDA08030107), and the Natural Science Foundation of Hebei Province (C2016503015).

*The $\boldsymbol{e}$-Xtra logo stands for "electronic extra" and indicates that three supplementary tables are published online.

Accepted for publication 22 November 2017.

C) 2018 The American Phytopathological Society losses of about 10 million tons per annum (http://www.natesc.agri.cn/). However, only $16.9 \%$ of the modern commercial wheat cultivars are resistant to multiple isolates of powdery mildew, and only 3.4 and $4.2 \%$ of the landraces and improved cultivars, respectively, are resistant to isolate E09 (the prevalent isolate in Northern China) (Li et al. 2011). More and more powdery mildew resistance $(\mathrm{Pm})$ genes, including $P m 1, P m 3, P m 4$, and $P m 8$ existing in wheat cultivars, have become ineffective against powdery mildew in China (Ma et al. 2014). For instance, $P m 21$ was one of the most effective $P m$ genes existing in Chinese cultivars, and was defeated by the variant isolates of $B$. graminis f. sp. tritici in recent years (Ren et al. 2011; Shi et al. 2009). Therefore, it is important to identify more effective resistance genes against powdery mildew to increase genetic diversity in wheat.

To date, more than 70 formally and 30 temporarily designated $\mathrm{Pm}$ genes and alleles have been documented in different genotypes since 1953, when the first $P m$ gene, $P m 1$, was identified in the wheat genotypes Thew and Norka (McIntosh et al. 2016; Pugsley and Carter 1953; Zhang et al. 2016). In general, the deployment of a specific $P m$ gene in wheat improvement depends on its effectiveness and the agronomic performance of its donor. Because of linkage drag, competition drag, and adverse pleiotropism, not all effective genes can be readily used for genetic improvement of powdery mildew resistance (Summers and Brown 2013). Therefore, the identification of new genes or allelic variations in cultivars or breeding lines offers an attractive prospect for developing resistant cultivars. In fact, several cultivars with broad-spectrum resistance have being widely used in some wheat production regions; these include Jimai 22 (PmJM22) (Yin et al. 2009), Liangxing 66 (PmLX66) (Huang et al. 2012), Liangxing 99 (Pm52) (Zhao et al. 2013), and Wennong 14 (PmW14) (Song et al. 2014) in Shandong Province; YingBo 700 (PmYB) (Ma et al. 2015c) in Hebei Province; Yumai 66 (PmYm66) (Hu et al. 2008) and Zheng 9754 (PmHNK54) (Xu et al. 2011) in Henan Province; and Zhongmai 155 (PmZ155) (H. G. Sun et al. 2015) in the Beijing area. These resistant cultivars can be directly recommended to the appropriate growing regions. Alternatively, the $P m$ genes in these cultivars can be rapidly transferred to other susceptible cultivars with excellent agronomic performance. 
With the development of the molecular markers, marker-assisted selection (MAS) provides a valuable complement to conventional breeding, and has been incorporated successfully in many breeding programs in the world for resistant cultivar development (Gupta et al. 2010). In MAS, closely linked markers that are available for breeding play a key role in detecting targeted genes in the progenies. In the past, the major markers used for MAS were restriction fragment length polymorphism, expressed sequence tag (EST), sequence tag site (STS), and simple-sequence repeat (SSR) markers. However, the density of those markers is relatively low under the premise of the large and complex wheat genome, which seriously limits their selection efficiency in MAS. With the development of high-throughput sequencing and automated genotyping platforms, single-nucleotide polymorphism (SNP)-derived markers have been preferably used to construct high-density genetic maps and for MAS because of their abundant numbers in the wheat genome (Kassa et al. 2016; Mora et al. 2015).

Our previous work suggests that the wheat breeding line $10 \mathrm{~V}-2$ has a broad resistance spectrum to different $B$. graminis f. sp. tritici isolates at the seedling stage and a high level of powdery mildew resistance to a mixture of $B$. graminis $\mathrm{f}$. sp. tritici isolates at the adult stage. In addition, $10 \mathrm{~V}-2$ possesses satisfactory agronomic traits in the field, indicating that it is an attractive source of resistance for powdery mildew. Therefore, the objectives of the present work were to (i) evaluate the agronomic performance of $10 \mathrm{~V}-2$ in the field in comparison with representative high-yielding cultivars in China, (ii) assess the powdery mildew resistance of $10 \mathrm{~V}-2$ in comparison with the representative resistant cultivars in China, (iii) analyze the inheritance of its seedling resistance to different $B$. graminis f. sp. tritici isolates and to map the resistance genes, (iv) develop new markers for increasing marker density in the targeted interval, (v) compare its reaction pattern with other donors with documented $P m$ genes using different $B$. graminis f. sp. tritici isolates, and (vi) screen the molecular markers available for MAS and incorporate the resistance genes into breeding programs.

\section{Materials and Methods}

Plant materials. A common winter wheat breeding line of unknown pedigree, $10 \mathrm{~V}-2$, was used as the donor of resistance genes against powdery mildew. It has been maintained in our lab as a valuable resource resistant to powdery mildew, and has been continuously grown for 5 years in Northern China to evaluate its desirable agricultural traits and high powdery mildew resistance. The susceptible cultivar Shimai 15 was crossed with $10 \mathrm{~V}-2$ to obtain $F_{2}$ and $F_{2: 3}$ populations for genetic analysis of powdery mildew resistance in $10 \mathrm{~V}-2$. Wheat cultivar Huixianhong, which is susceptible to all of the $B$. graminis f. sp. tritici isolates tested in the past (Ma et al. 2016a), was used as the susceptible control for phenotypic evaluation. Eleven resistant donors with documented $P m$ genes on chromosome arm 5DS (Supplementary Table S1) were maintained in our lab and used to compare their phenotypic responses to different B. graminis f. sp. tritici isolates with those of $10 \mathrm{~V}-2$. To assess the breeding value of $10 \mathrm{~V}-2$ against powdery mildew in different regions, its multi-isolate response was compared with several representative commercial resistant cultivars (e.g., Laingxing 66, Wennong 14, YingBo 700, Liangxing 99, Jimai 22, and Liangxing 99) that are widely grown in the Huanghuai region of China, including Henan, Shandong, Hebei, Shaanxi, Shanxi, Northern Jiangsu, and Northern Anhui Provinces. Thirteen representative commercial cultivars widely grown in the Huanghuai region of China were used as references for evaluating the agronomic performance of $10 \mathrm{~V}-2$ (Table 1). Forty-nine wheat cultivars or breeding lines from China were evaluated with closely linked markers to detect the $\mathrm{Pm}$ genes in their genetic backgrounds (Supplementary Table S2). Several markers were then selected and used to transfer the $\mathrm{Pm}$ genes in $10 \mathrm{~V}-2$ into other breeding materials. For homology-based cloning of $P m 2$ alleles, wheat cultivar Chinese Spring was used as the negative control because it does not carry the $P m 2$ allele.

Agronomic performance. The breeding line $10 \mathrm{~V}-2$ and 13 released commercial cultivars (Table 1) from the Huanghuai region were planted in a field at Luancheng Agro-Ecological Experimental Station (37 $\left.53^{\prime} 15^{\prime \prime} \mathrm{N}, 114^{\circ} 40^{\prime} 47^{\prime \prime} \mathrm{E}\right)$, Chinese Academy of Sciences, Shijiazhuang, China. Sowing and assessment were carried out based on the methods described by Xu et al. (2014). The plots for each cultivar were $1.5 \mathrm{~m}$ long and $1.0 \mathrm{~m}$ wide, with four rows per plot and 30 seeds per row. Ten plants in the middle of the two internal rows were sampled to assess the plant height (PH), spike length (SL), spike numbers per plant (SNPP), spikelet numbers per spike (SNS), sterile spikelet numbers per spike (SSNS), kernel numbers per spike (KNS), and thousand-kernel weight (TKW). PH and SNPP were determined based on the mean of 10 plants. SL, SNS, KNS, and SSNS were determined based on the mean of the primary spikes of the 10 plants. TKW was evaluated after harvest through weighing three samples of 500 kernels. Analysis of variance of each trait was performed using SPSS 16.0 software (SPSS Inc, Chicago). The least significant difference test was conducted to assess the significance of difference between $10 \mathrm{~V}-2$ and the representative commercial cultivars for each trait. A $P<0.05$ probability level was selected.

Disease assessment and phenotyping reactions to powdery mildew. From 2011 to 2016, 10V-2 and 13 representative resistant cultivars and lines were planted in field trials and the greenhouse simultaneously. The field trails were the same as that for agronomic performance, with the susceptible control Huixianhong planted every eight rows to make sure every plot was adjacent to the control. In the spring of each year, the Huixianhong seedlings were inoculated with a mixture of the $B$. graminis f. sp. tritici isolates from different wheat regions in China. At full heading and filling stages, infection types (IT) were rated using a 0 -to- 9 scale, where 0 to 4 was resistant and

Table 1. Agronomic performance of wheat breeding line $10 \mathrm{~V}-2$ and 13 representative commercial cultivars in the Huanghuai region of China ${ }^{\mathrm{a}}$

\begin{tabular}{|c|c|c|c|c|c|c|c|}
\hline Cultivars & PH (cm) & SL (cm) & SNPP & SNS & KNS & SSNS & TKW (g) \\
\hline $10 \mathrm{~V}-2$ & $74.3 \pm 1.7$ & $8.2 \pm 0.5$ & $10.3 \pm 0.5$ & $18.7 \pm 0.5$ & $56.3 \pm 4.5$ & $0.0 \pm 0.0$ & $49.8 \pm 1.0$ \\
\hline Shimai 15 & $76.3 \pm 2.4$ & $8.3 \pm 0.4$ & $10.3 \pm 0.9$ & $19.7 \pm 0.5$ & $53.7 \pm 3.7$ & $1.0 \pm 0.0^{*}$ & $51.1 \pm 0.9$ \\
\hline Ji 5265 & $69.0 \pm 2.8^{*}$ & $7.6 \pm 0.6$ & $11.0 \pm 0.8$ & $19.7 \pm 0.9$ & $52.7 \pm 0.9$ & $1.0 \pm 0.0^{*}$ & $46.2 \pm 1.5$ \\
\hline Gao 8901 & $79.7 \pm 3.7 *$ & $8.8 \pm 0.2$ & $11.3 \pm 1.2$ & $20.3 \pm 0.9$ & $56.3 \pm 7.6$ & $1.3 \pm 0.5^{*}$ & $53.4 \pm 1.0$ \\
\hline Han 6172 & $74.7 \pm 2.1$ & $8.7 \pm 0.2$ & $11.0 \pm 0.8$ & $17.7 \pm 0.5$ & $52.3 \pm 0.5$ & $0.0 \pm 0.0$ & $50.1 \pm 1.0$ \\
\hline Kenong 9204 & $67.3 \pm 3.1^{*}$ & $7.5 \pm 0.6$ & $12.3 \pm 0.5^{*}$ & $17.7 \pm 1.2$ & $49.3 \pm 6.8$ & $0.7 \pm 0.5$ & $45.1 \pm 0.7^{*}$ \\
\hline Shi 4185 & $75.3 \pm 0.9$ & $8.8 \pm 0.2$ & $11.7 \pm 0.5^{*}$ & $21.0 \pm 0.0^{*}$ & $61.7 \pm 2.4$ & $0.0 \pm 0.0$ & $50.5 \pm 1.8$ \\
\hline Wennong 14 & $74.3 \pm 2.6$ & $8.4 \pm 0.3$ & $8.0 \pm 0.8^{*}$ & $17.3 \pm 0.5^{*}$ & $46.0 \pm 2.9^{*}$ & $0.0 \pm 0.0$ & $49.8 \pm 2.1$ \\
\hline Zhongmai 155 & $74.3 \pm 4.1$ & $8.7 \pm 0.2$ & $7.3 \pm 0.5^{*}$ & $17.7 \pm 1.9$ & $56.7 \pm 2.9$ & $0.0 \pm 0.0$ & $49.8 \pm 1.1$ \\
\hline Luyuan 502 & $70.7 \pm 0.9$ & $9.6 \pm 0.3^{*}$ & $9.3 \pm 0.5^{*}$ & $19.3 \pm 0.5$ & $55.3 \pm 2.4$ & $0.3 \pm 0.5$ & $47.3 \pm 0.3$ \\
\hline Jimai 22 & $70.7 \pm 1.7$ & $8.4 \pm 0.6$ & $10.3 \pm 0.5$ & $19.0 \pm 0.0$ & $49.7 \pm 1.7$ & $0.0 \pm 0.0$ & $47.3 \pm 0.8$ \\
\hline Liangxing 66 & $73.3 \pm 2.9$ & $8.7 \pm 0.3$ & $8.3 \pm 1.2^{*}$ & $19.0 \pm 0.0$ & $52.3 \pm 4.6$ & $0.0 \pm 0.0$ & $49.1 \pm 0.6$ \\
\hline Liangxing 99 & $77.3 \pm 2.1$ & $8.8 \pm 0.2$ & $10.0 \pm 0.8$ & $18.7 \pm 0.5$ & $52.0 \pm 5.0$ & $0.0 \pm 0.0$ & $51.8 \pm 0.9$ \\
\hline Tainong 18 & $70.0 \pm 1.6$ & $8.6 \pm 0.1$ & $9.7 \pm 0.5$ & $18.7 \pm 0.5$ & $62.0 \pm 1.6$ & $0.0 \pm 0.0$ & $46.9 \pm 1.1$ \\
\hline
\end{tabular}

${ }^{\text {a }} \mathrm{PH}=$ plant height, $\mathrm{SL}=$ spike length, SNPP = spike number per plant, SNS = spikelet number per spike, KNS = kernel number per spike, SSNS = sterile spikelet number per spike, and TKW $=$ thousand-kernel weight. For the same trait, the cultivars indicated by an asterisk $(*)$ were significantly different with $10 \mathrm{~V}-2$ at $P<0.05$ probability based on the least significant difference test. 
5 to 9 susceptible (Sheng and Duan 1991). The same procedure was repeated for 6 years to confirm the phenotypic evaluation data.

In the greenhouse at Shijiazhuang, 10V-2 and the 13 host lines were tested to determine their seedling reaction patterns to multiple $B$. graminis f. sp. tritici isolates with different avirulence or virulence patterns and collected from different wheat production regions of China. For each line, 20 seeds were sown in 128-well rectangular trays in a growth chamber, with 5 seeds per 3-by-3-cm well. The susceptible control Huixianhong was planted randomly in the trays. At the one- to two-leaf stage, seedlings were inoculated with fresh conidiospores increased on Huixianhong seedlings and incubated in a dark chamber at $18^{\circ} \mathrm{C}$ for $24 \mathrm{~h}$. Then, the rectangular trays were placed in a greenhouse with a daily cycle of $14 \mathrm{~h}$ of light at $22^{\circ} \mathrm{C}$ and $10 \mathrm{~h}$ of darkness at $18^{\circ} \mathrm{C}$. When the pustules were fully developed on the susceptible control Huixianhong, the seedling reactions to powdery mildew were evaluated using the 0 -to- 4 scale described by Si et al. (1992) and Ma et al. (2016a), in which IT 0, 0;, 1, and 2 were regarded as resistant and IT 3 and 4 as susceptible. To confirm the phenotypic data, these phenotypic tests were repeated three times using the same procedure.

B. graminis f. sp. tritici isolate B03 was selected to inoculate seedlings of $10 \mathrm{~V}-2$, Shimai 15 , and their $F_{1}, F_{2}$, and $F_{2: 3}$ progenies for genetic analysis. For each $\mathrm{F}_{2: 3}$ family, 40 plants were tested against $\mathrm{B} 03$. Goodness-of-fit were investigated using a $\chi^{2}$ test to assess deviations of the observed phenotypic data from theoretically expected segregation ratios using SPSS 16.0 software (SPSS Inc.) with a $P$ value level of 0.05 . If the segregating ratio was consistent with single-gene segregation, then all other avirulent $B$. graminis $\mathrm{f}$. sp. tritici isolates were used for genetic analysis to confirm whether the same gene was responsible for resistance to all of the avirulent $B$. graminis f. sp. tritici isolates.

Preliminary molecular marker analysis. Genomic DNA of 10V2 , Shimai 15 , and the $F_{2}$ plants were isolated from the young leaf tissues soon after phenotypic evaluation following the cetyletrimethylammonium bromide protocol (Saghai-Maroof et al. 1984). Resistant and susceptible DNA bulks were constructed by separately mixing equal amount of DNA from 10 homozygous resistant and 10 homozygous susceptible $F_{2}$ plants, respectively. For preliminary molecular marker analysis, 50 SSR markers that can detect documented $\mathrm{Pm}$ genes or alleles were tested for polymorphisms between the parents and bulks. Then, 15 markers located in the targeted interval were tested against the parents and bulks. Polymorphic markers between the parents and bulk segregants were then used to genotype the $\mathrm{F}_{2}$ population of $10 \mathrm{~V}-2 \times$ Shimai 15 .

Development of new markers using bulked segregant RNASeq. When the $P m$ gene in $10 \mathrm{~V}-2$ was preliminarily mapped in the $P m 2$ interval, the previously completed bulked segregant RNA-Seq (BSR-Seq) data for the documented $P m 2 b$ stock KM2939 were used to develop new markers to saturate the linkage map in this interval. Through BSR-Seq, associated SNP or gene sequences in the Pm2 interval were identified and used for marker development in BMK Cloud (developed by Biomarker Technologies Corporation, Beijing, China). All markers in this interval were tested for polymorphisms between the parents and bulks. The resulting markers were genotyped on the $\mathrm{F}_{2}$ population of $10 \mathrm{~V}-2 \times$ Shimai 15 .

Map construction. When the reaction patterns of the $\mathrm{F}_{2: 3}$ families were confirmed, a $\chi^{2}$ test was used to assess deviations of the observed phenotypic data from theoretically expected segregation ratios for goodness-of-fit. The method for constructing the linkage map of the Pm genes was based on Lincoln et al. (1993) and Kosambi (1943) using MAPMAKER 3.0 and the Kosambi function.

Molecular and genetic comparison of the $P m$ gene in $10 \mathrm{~V}-2$ with the cloned Pm2 sequence. A homologous sequence of $10 \mathrm{~V}$ 2 was cloned using homology-based cloning based on the previous report in cloning a $P m 2$ allele, $P m 2 a$ (Sánchez-Martín et al. 2016). The first exon was amplified using primers JS320 (forward $5^{\prime}-3^{\prime}$ : ACGATGATGTGAATCTTCCGTG) and JS305 (reverse 5' $-3^{\prime}$ : AAT GATAGCATGCATTTGGAG). Then, a nested polymerase chain reaction (PCR) was carried out to obtain the final sequence of the first exon using primers JS314 (forward 5'-3': TTTTCGCGGTATTGCTGGTG) and JS315 (reverse 5'-3': ACCTCCTGTCATCGGTTCAC). The second and third exons were obtained using JS350 (forward 5' $-3^{\prime}$ :
CCCTCCTCCTTGAAGAATCTGA) and JS313 (reverse 5'-3': GCAC AAACTCTACCCTGTTCC). Then, the sequences amplified from $10 \mathrm{~V}-2$ were assembled and compared with the cloned sequence of Pm2a after Sanger sequencing.

Based on the sequence divergence of the first exon amplified from $10 \mathrm{~V}-2$ and Chinese Spring, two pairs of STS primers SWGI067 (forward 5'-3': CCTGGGAGGGCTCGGATCACTG, reverse 5'-3': GGAGGGATGAGCGGTTCTGTAG) and SWGI068 (forward 5'-3': CAAATGCCAGAAACTGAGGGAA, reverse: GGAGGGA TGAGCGGTTCTGTAG) were designed to amplify the sequence covering the polymorphic sequences of the interval. Then, those markers were used to genotype the $\mathrm{F}_{2: 3}$ families of $10 \mathrm{~V}-2 \times$ Shimai 15 . If the cloned sequence of $10 \mathrm{~V}-2$ was, indeed, PmlOV-2, then the markers should cosegregate with the phenotype of $\mathrm{F}_{2: 3}$ families of $10 \mathrm{~V}-2 \times$ Shimai 15. Otherwise, $P m 10 \mathrm{~V}-2$ may be different from the cloned sequence of Pm2a. Fifty SSR markers randomly distributed on 21 chromosomes of wheat were used to detect the genetic backgrounds of the recombinants to avoid false hybrid strains. If amplified bands of some plants were not consistent with those of $10 \mathrm{~V}-2$ or Shimai 15 , these plants were most likely false hybrid strains and may not be recombinants.

Evaluation of the closely linked markers for MAS. To evaluate the polymorphisms of the closely linked markers of $\mathrm{Pm}$ genes in $10 \mathrm{~V}-2$ for MAS, 49 wheat cultivars or breeding lines from China were tested using the markers Cfd81, Bwm20, Bwm21, Bwm25, Swgi029, Swgi038, and Swgi064. The polymorphic bands amplified from these cultivars or breeding lines and $10 \mathrm{~V}-2$ were compared based on the methodology of Ma et al. (2016b). The markers that amplified polymorphic bands between $10 \mathrm{~V}-2$ and these cultivars or breeding lines were regarded to be applicable in MAS.

\section{Results}

Evaluation of agronomic performance in the field. Line $10 \mathrm{~V}-2$ showed satisfactory agronomic performance for the investigated traits (PH, SL, SNPP, SNS, SSNS, KNS, and TKW) compared with 13 representative commercial cultivars in Huanghuai regions of China (Table 1). Its grain-filling characteristics and fertility were much better than or similar to those of the commercial cultivars; even its basal spikelets were all fertile (Table 1). No obvious disadvantages were observed for 10V-2. This suggests that $10 \mathrm{~V}-2$ has desirable agronomic performance and, hence, is a competitive wheat breeding line for agronomic traits.

Evaluation of powdery mildew resistance of $10 \mathrm{~V}-2$. Over six consecutive growing seasons, $10 \mathrm{~V}-2$ showed a high level of adult-plant resistance to a mixture of $B$. graminis $\mathrm{f}$. sp. tritici isolates in the field and the greenhouse, with IT of 0 to 2, whereas Huixianhong was highly susceptible, with IT of 8 to 9 . At the seedling stage, the $49 \mathrm{~B}$. graminis f. sp. tritici isolates had an avirulence frequency of $93.9 \%$ on $10 \mathrm{~V}-2$.

Inheritance of powdery mildew resistance in $10 \mathrm{~V}-2$. When inoculated with $B$. graminis f. sp. tritici isolate B03 at the seedling stage, $10 \mathrm{~V}-2$ was immune, with an IT rating of 0 , whereas Shimai 15 was highly susceptible, with an IT rating of 4 . For the cross of $10 \mathrm{~V}-2 \times$ Shimai 15 , all $\mathrm{F}_{1}$ plants showed an immune reaction, with an IT rating of 0. This reaction was similar to the resistant parent $10 \mathrm{~V}-2$, indicating the dominance nature of the resistance gene. The segregation ratios of the $F_{2}$ and $F_{2: 3}$ populations are shown in Table 2 . The $F_{2}$ population segregated into 121 resistant and 37 susceptible $F_{2}$ plants, which was identical to a ratio of monogenic segregation. The $\mathrm{F}_{2: 3}$ families segregated

Table 2. Segregation ratios of $\mathrm{F}_{2}$ and $\mathrm{F}_{2: 3}$ generations of $10 \mathrm{~V}-2 \times$ Shimai 15 following inoculation with Blumeria graminis f. s. tritici isolate $\mathrm{B} 03$ at the seedling stage

\begin{tabular}{lccccccc}
\hline \multicolumn{9}{c}{$\begin{array}{c}\text { Plants } \\
\text { observed }\end{array}$} & & & & \\
\cline { 2 - 4 } Cross & HR & Seg & HS & Expected ratio & $\boldsymbol{\chi}^{\mathbf{2 b}}$ & $\boldsymbol{P}$ \\
\hline 10V-2/Shimai $15 \mathrm{~F}_{2}$ & 121 & 37 & $3: 1$ & 0.10 & 0.75 \\
10V-2/Shimai $15 \mathrm{~F}_{2: 3}$ & 36 & 59 & 33 & $1: 2: 1$ & 0.92 & 0.63 \\
\hline
\end{tabular}

${ }^{\mathrm{a}} \mathrm{HR}=$ homozygous resistant, $\mathrm{Seg}=$ segregating, and $\mathrm{HS}=$ homozygous susceptible.

b Values of $\chi^{2}$ for statistical significance at $P=0.05$ are $3.84(1 \mathrm{df})$ and $5.99(2 \mathrm{df})$. 
into 36 homozygous resistant (RR), 59 segregating (Rr), and 33 homozygous susceptible (rr) plants, which confirmed the ratio for monogenic segregation. The gene that conferred resistance to $B$. graminis f. sp. tritici isolate B03 in 10V-2 was tentatively designated Pm10V-2.

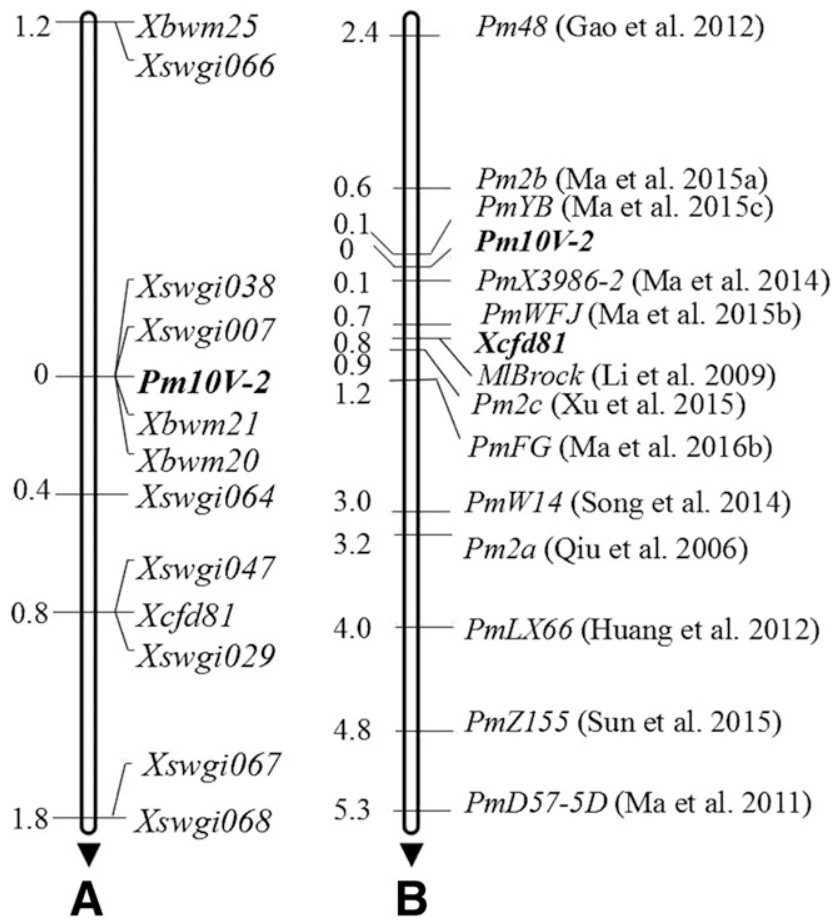

Fig. 1. A, Linkage map of Pm10V-2 using the $F_{2: 3}$ families of $10 \mathrm{~V}-2 \times$ Shimai 15 and $B$, its locus comparison with the reported powdery mildew resistance $(P m)$ genes in the Pm2 interval of chromosome arm 5DS using the anchoring marker locus Xcfd81. Genetic distances in centimorgans are shown to the left. Pm10V-2 locus was set as the zero point. The black arrow points to the centromere.

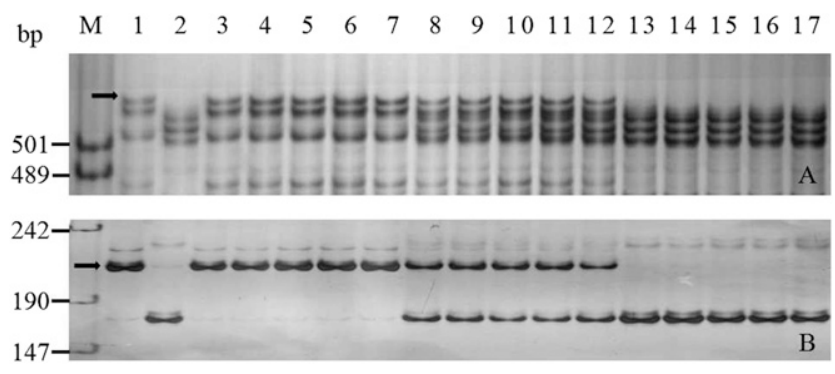

Fig. 2. Amplification patterns of bulked segregant RNA-Seq-derived markers A, Swgi038 and B, Swgi064 in genotyping 10V-2, Shimai 15 , and selected $F_{2: 3}$ families of 10V-2 $\times$ Shimai 15. Lane M, pUC18 Mspl; lanes 1 and 2, 10V-2 and Shimai 15 ; lanes 3 to 7 , homozygous resistant $F_{2: 3}$ families; lanes 8 to 12 , homozygous susceptible $F_{2: 3}$ families; and lanes 13 to 17 , heterozygous $F_{2: 3}$ families. Black arrows indicate the 520-bp (A) and 216-bp (B) polymorphic bands in 10V-2.
To determine the inheritance of resistance to other $B$. graminis $\mathrm{f}$. sp. tritici isolates, all other $B$. graminis $\mathrm{f}$. $\mathrm{sp}$. tritici isolates avirulent to $10 \mathrm{~V}-2$ were used to test against 10 randomly selected homozygous resistant (numbers 2, 7, 13, 14, 15, 19, 21, 22, 24, and 27), 10 segregating (numbers $1,3,4,9,16,26,34,36,41$, and 44)m and 10 homozygous susceptible (numbers $49,50,53,64,68,77,81,85,88$, and 106) $\mathrm{F}_{2 \cdot 3}$ families. The reactions of all these $B$. graminis $\mathrm{f} . \mathrm{sp}$. tritici isolates were exactly the same as those for B03. This indicated that the resistance to all avirulent $B$. graminis f. sp. tritici isolates in $10 \mathrm{~V}-2$ was controlled by the same gene, Pm10V-2.

Molecular mapping of $\mathbf{P m 1 0 V - 2}$. The marker $C f d 81$ linked to the gene $P m 2$ showed polymorphism between $10 \mathrm{~V}-2$, Shimai 15 , and their derived resistant and susceptible bulks. The $\mathrm{F}_{2: 3}$ population of $10 \mathrm{~V}-2 \times$ Shimai 15 was then genotyped using Cfd81. Two recombination events were detected and the genetic distance of 0.8 centimorgans (cM) from Pm10V-2 was accordingly estimated. To confirm the position of the Pm10V-2 locus, Pm2-linked markers Bwm25, $B w m 20$, and Bwm21 developed by Lu et al. (2015) were used to test the $\mathrm{F}_{2: 3}$ population. Polymorphisms were observed between the resistant and susceptible bulks and the parents. Bwm25 was linked to $P m 10 V-2$ at a genetic distance of $1.2 \mathrm{cM}$, while the other two markers, Bwm 20 and Bwm21, cosegregated with Pm1OV-2. Therefore, $P m 10 \mathrm{~V}-2$ was mapped on chromosome arm 5DS with a loci order of Cfd81-Pm10V-2/Bwm20/Bwm21-Bwm25 (Fig. 1). Based on the previous reports (Lu et al. 2015), the flanking markers $C f d 81$ and Bwm25 were mapped to the deletion bin 5DS1-0-0.63; therefore, Pm10V-2 should also be assigned to this same bin.

To saturate the linkage map of the Pm10V-2 interval, the result of BSR-Seq for $P m 2 b$ was used for developing new markers linked to the Pm2 locus. Based on the sequences of the SNP in the Pm2 interval and their alignment with the wheat reference sequence, 66 markers were designed (Supplementary Table S3). Of these markers, two SNP markers (Swgi047 and Swgi064), three EST markers (Swgi007, Swgi029, and Swgi038), and one SSR marker (Swgi066) showed polymorphisms between the parents and the resistant and susceptible bulks, and were also closely linked with $\mathrm{Pm} 10 \mathrm{~V}-2$ (Figs. 1 and 2; Table 3). Finally, a linkage map spanning $2.4 \mathrm{cM}$ on chromosome arm 5DS was constructed and combined with previously screened SSR markers. Pm10V-2 was flanked by the new markers Swgi064 and SwgiO66 at genetic distances of 0.4 and 1.2 $\mathrm{cM}$, respectively, and cosegregated with new markers $\mathrm{Swgi007}$ and Swgi038 (Fig. 1).

Multi-isolate reaction comparisons of $P m 10 V-2$ and the previously reported $P \boldsymbol{m}$ genes or alleles at or near the $P \boldsymbol{m} 2$ locus. When tested against $49 \mathrm{~B}$. graminis f. sp. tritici isolates, Pm10V-2 has a clearly different response spectrum from those of documented $\mathrm{Pm}$ genes on chromosome arm 5DS. This information combined with the position of the locus of $P m 1 O V-2$ and $P m 2$ alleles indicated that $P m 10 V-2$ should be considered as either a new $P m$ gene or a new Pm2 allele.

Comparison of $P m 10 \mathrm{~V}-2$ and the $P m 2$ sequences. Using primers JS320 and JS305, a 4,825-bp sequence, including the first exon, was obtained from 10V-2 and Ulka/8*Cc (Pm2a) after Sanger sequencing. Then, the first exon of 3,730 bp was obtained through Sanger sequencing the nested PCR products and amplified using the 4,825-bp

Table 3. New polymorphic markers developed using bulked segregant RNA-Seq (BSR-Seq) homologous sequence divergence of the first exon of the Pm2a from $10 \mathrm{~V}-2$ and Chinese Spring for the powdery mildew resistance gene Pm10V-2

\begin{tabular}{|c|c|c|c|c|}
\hline Markers & Forward primer $\left(5^{\prime}-3^{\prime}\right)$ & Reverse primer $\left(5^{\prime}-3^{\prime}\right)$ & Product size (bp) & Marker type $^{\mathbf{a}}$ \\
\hline SWGIO07 & CCAAATGCTACAGCGCCTTG & GTTGCCTTGCCGATTTCTGG & 325 & EST \\
\hline SWGIO29 & CGGTGCACATTTCCATGGCT & ATGCTGAAGATCACCACCGC & 446 & EST \\
\hline SWGI038 & GGGAACAACATCCCGCTGTC & GGAGATGAGGCTGGCGTAG & 530 & EST \\
\hline SWGI047 & AAAATCCTCGCGACAATGAC & ATGATCAAGGGCAGCAAATC & 316 & SNP \\
\hline SWGI064 & AGGAGGCCAAGAAGGAGAAG & CCCGACTTAATAACCGTCCA & 216 & SNP \\
\hline SWGIO66 & TGCCACATCCTGAACCACTA & CTTGTTAGCCTCCTTCGTGC & 340 & SSR \\
\hline SWGI067 & CCTGGGAGGGCTCGGATCACTG & GGAGGGATGAGCGGTTCTGTAG & 1,500 & STS \\
\hline SWGI068 & CAAATGCCAGAAACTGAGGGAA & GGAGGGATGAGCGGTTCTGTAG & 340 & STS \\
\hline
\end{tabular}

${ }^{\mathrm{a}} \mathrm{EST}=$ expressed sequence tag, $\mathrm{SNP}=$ single-nucleotide polymorphism, $\mathrm{SSR}=$ simple-sequence repeat, and STS = sequence tag site. 
DNA as template. The sequence of the first exon of $10 \mathrm{~V}-2$ was identical to that of $P m 2 a$. The second and third exons of $10 \mathrm{~V}-2$ were amplified using the primers JS350 and JS313, respectively. After Sanger sequencing, the 58-bp exon 2 and 46-bp exon 3 were obtained, which were identical to the second and third exons of $P m 2 a$, respectively. Therefore, the newly cloned coding sequence from $10 \mathrm{~V}-2$ was identical to that of Pm2a.

To confirm whether the newly cloned sequence was correlated with the powdery mildew resistance in $10 \mathrm{~V}-2$, the markers $S W G I 067$ and SWGIO68 were tested for $10 \mathrm{~V}-2$, Shimai 15 , and the resistant and susceptible bulks. It consistently amplified polymorphisms between the parents and the resistant and susceptible bulks. Then, SWGI067 and SWGI068 were used to genotype the $141 \mathrm{~F}_{2: 3}$ families of $10 \mathrm{~V}$ $2 \times$ Shimai 15 . Two recombinants (numbers 105 and 126) were detected in the $\mathrm{F}_{2: 3}$ families. These two $\mathrm{F}_{2: 3}$ families had homozygous resistant genotypes, which were the same as the resistant parent $10 \mathrm{~V}$ 2. To avoid false hybrids, 50 SSR markers randomly distributed on 21 chromosomes of wheat were used to examine the genetic backgrounds of the two recombinants. The results indicated that the genetic backgrounds of the recombinants were similar to their parents. Therefore, the SWGIO67 and SWGIO68 alleles in the first exon were located at some genetic distance from Pm10V-2. After calculation using the software Mapmarker 3.0, SWGIO67 and SWGIO68 were both mapped to the $P m 10 \mathrm{~V}-2$ interval at a genetic distance of $1.8 \mathrm{cM}$ (distal) (Fig. 1). Thus, the Pm1OV-2 gene was different from the documented sequence of $P m 2 a$.

Evaluation of closely linked markers for MAS. The markers closely linked to $\mathrm{Pm} 10 \mathrm{~V}$-2 were used to test 49 Chinese representative cultivars and lines. In addition to the documented markers $C f d 81$, $B w m 20, B w m 21$, and Bwm25, the newly developed SWGIO29, SWGI038, and SWGIO64 alleles in most of the tested cultivars were also different from those in $10 \mathrm{~V}-2$. This demonstrated that they could be used in MAS for detecting Pm10V-2 in those genetic backgrounds (Fig. 3). However, this was not the case for all of the marker alleles in cultivar Jimai 22; for Bwm20, SWGIO38, and SWGIO64 in cultivar Tainong 18; and for SWGIO64 allele in cultivar Jinmai 41.

\section{Discussion}

Line $10 \mathrm{~V}-2$ is a wheat breeding line from Hebei Province of China with a high level of resistance to powdery mildew that is stable during all growth stages. This stable resistance across growth stages makes $10 \mathrm{~V}-2$ a valuable resource for wheat breeding. Compared with other resistant cultivars currently deployed in the Huanghuai region of China, 10V-2 possesses a broader resistance spectrum than most other cultivars. A single dominant gene, Pm10V-2, confers the seedling powdery mildew resistance in $10 \mathrm{~V}-2$. Using various molecular markers, $P m 10 V$ - 2 was mapped in the $P m 2$ interval on chromosome arm 5DS, on which several $P m$ genes have been reported, including $P m 2 a$ (Qiu et al. 2006), Pm2b (Ma et al. 2015a), Pm2c (Xu et al. 2015), Pm48 (Gao et al. 2012), PmLX66 (Huang et al. 2012; Y. L. Sun et al. 2015), $P m Y B$ (Ma et al. 2015b), PmZ155 (H. G. Sun et al. 2015), PmWFJ (Ma et al. 2015c), PmFG (Ma et al. 2016b), PmW14 (Song et al. 2014; Y. L. Sun et al. 2015), PmD57-5D (Ma et al. 2011), and PmX3986-2 (Ma et al. 2014). Through resistance spectrum analysis, $10 \mathrm{~V}-2$ showed a broad-spectrum powdery mildew resistance, and $P m 10 V-2$ could be distinguished from the other documented genes in the Pm2 interval. Recently, a Pm2a-related sequence was cloned using mutant chromosome sequencing (Sánchez-Martín et al. 2016). Pm10V-2 was closely linked but not cosegregate with the cloned Pm2-related sequence, indicating that gene Pm10V-2 is different from this sequence. $P m 10 V-2$ would serve as a valuable resistance resource to increase the diversity of the resistance genes in wheat breeding against powdery mildew. Additional allelism tests between Pm1OV-2 and the documented Pm genes in the Pm2 interval are still required in the near future to determine their allelic relationship.

In this study, more markers were developed using BSR-Seq and were added to the $P m 10 \mathrm{~V}$-2 linkage map compared with previously reported linkage maps of the $P m 2$ interval (Ma et al. 2016b). The newly developed markers increased the marker density in the Pm2 interval, which will accelerate the map-based cloning of the Pm2 alleles. These markers could also be used in MAS. Genome and transcriptome data had been increasingly used in molecular marker development and genetic linkage mapping (Duarte et al. 2014; Edae et al. 2016). BSR-Seq provides a highly effective genetic mapping strategy that combines the power of bulked segregant analysis and RNA-Seq (Liu et al. 2016). A number of valuable genes in common wheat have been mapped or their marker density increased using this technique, such as the $\mathrm{N}$-dependent LM gene ( $N d h r l 1)$ ( $\mathrm{Li}$ et al. 2016), the grain protein content gene GPC-BI (Trick et al. 2012), and the wheat yellow rust resistance gene $\operatorname{Yr} 15$ (Ramirez-Gonzalez et al. 2015). In this study, new SSR, EST, and SNP markers for the Pm2 allele were developed by using the BSR-Seq. They were all closely linked markers, and several of them are cosegregated with $P m 10 V-2$ in the tested population. Using this information, adjacent SNP were further analyzed, and the designed SNP markers were added in the interval.

When a valuable gene is identified, the potential value of its carrier in wheat improvement is largely determined by its agronomic traits. Resistance stocks with poor agronomic traits will slow down the breeding cycle and will not be widely accepted by breeders (Summers and Brown 2013). In the past, many $P m$ genes have been identified but few of them have been successfully used in modern breeding programs (Selter et al. 2014). Given that the wheat breeding line 10V-2 has agronomic, agricultural, and yield performance comparable with that of the currently grown commercial cultivars, and the Pm10V-2 gene has a broader resistance spectrum to different $B$. graminis f. sp. tritici isolates than most resistant cultivars in production, $10 \mathrm{~V}-2$ could not only serve as a valuable resistance resource to broaden the diversity of $\mathrm{Pm}$ genes for wheat improvement but also be used as a commercial cultivar. To use PmlOV-2 in MAS, we have crossed 10V-2 with several cultivars or lines such as Shiyou 17, Shi 4185, Ji 5265, Shixin 828, RS804, Shannong 17, Tainong 18, Yannong 19, Luyuan 502, and others that are suitable for commercialization in Hebei and Shandong Provinces, two of the main areas for wheat production in China. The $\mathrm{F}_{2}$ and $\mathrm{F}_{3}$ plants with linked marker alleles were selected using the corresponding marker. Combined with selection for agronomic performance in the field, head rows were planted in the $\mathrm{F}_{4}$ generation and, then, two cross combinations (Shi $4185 \times 10 \mathrm{~V}-2$ and $10 \mathrm{~V}-2 \times \mathrm{RS} 804$ ) with the best agronomic performance in the field were further evaluated in a field plot experiment. After comprehensive evaluation, several wheat breeding lines with good agronomic performance were selected. Among those lines, the wheat breeding line KM5016, $\mathrm{F}_{6}$ generation of $10 \mathrm{~V}-2 \times \mathrm{RS} 804$, was highly resistant to powdery mildew at both seedling and adult stages. The presence of closely linked markers alleles suggested that this line carries the Pm10V-2 gene. Wheat line KM5016 is currently being tested in a regional trial in Hebei

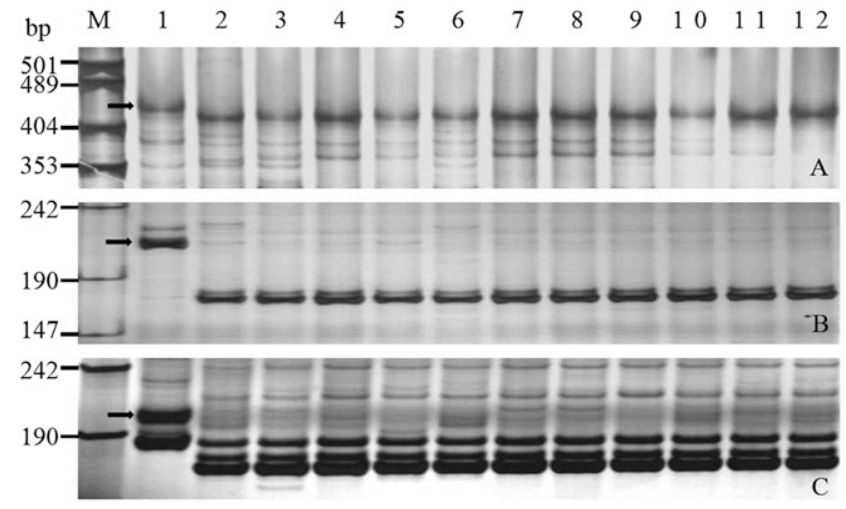

Fig. 3. Amplification patterns of Pm10V-2-linked markers A, Swgi029; B, Swgi064; and C, Bwm25 in 10V-2, Shimai 15, and selected wheat cultivars or breeding lines. Lane M, DNA marker pUC18 Mspl; lanes 1 and 2, 10V-2 and Shimai 15; and lanes 3 to 12, wheat cultivars in sequential order: Yanda 1817, Jimai 19, Chuanmai 42, Lumai 21, Zhengmai 9023, Yumai 34, Lumai 14, Yanmai 158, Yumai 18, and Zhou 8425B. Black arrows indicate the 446-bp (A), 216-bp (B), and 208-bp (C) polymorphic bands in 10V-2. 
Province. This study would provide a successful and thorough model of identification and confirmation of a new resistance gene in wheat, which includes the identification and evaluation of the powdery mildew gene using resistance spectrum analysis and genetic analysis, mapping of the gene using closely linked markers, and effective transferring of the gene into a superior agronomic background through MAS.

Although Pm10V-2 has been characterized and successfully used in wheat resistance breeding in the present work, further approaches are still required for fully exploring its potential. For example, functional markers to be used in MAS could be developed based on the sequence of Pm10V-2 gene. Kompetitive allele specific PCR markers (Rasheed et al. 2016) could be designed using the SNP associated with powdery mildew resistance to facilitate the transfer of Pm10V-2 using a high-throughput and automatic testing platform.

\section{Literature Cited}

Bedö, Z., and Láng, L. 2015. Wheat breeding: Current status and bottlenecks. Pages 77-101 in: Alien Introgression in Wheat. Springer, Cham, Switzerland.

Bennett, F. G. A. 1984. Resistance to powdery mildew in wheat: A review of its use in agriculture and breeding programmes. Plant Pathol. 33:279-300.

Duarte, J., Rivière, N., Baranger, A., Aubert, G., Burstin, J., Cornet, L., Lavaud, C., Lejeune-Hénaut, I., Martinant, J. P., Pichon, J. P., Pilet-Nayel, M. L., and Boutet, G. 2014. Transcriptome sequencing for high throughput SNP development and genetic mapping in Pea. BMC Genomics 15:126.

Edae, E. A., Olivera, P. D., Jin, Y., Poland, J. A., and Rouse, M. N. 2016. Genotype-by-sequencing facilitates genetic mapping of a stem rust resistance locus in Aegilops umbellulata, a wild relative of cultivated wheat. BMC Genomics 17:1039.

Gao, H. D., Zhu, F. F., Jiang, Y. J., Wu, J. Z., Yan, W., Zhang, Q. F., Jacobi, A., and Cai, S. B. 2012. Genetic analysis and molecular mapping of a new powdery mildew resistance gene Pm46 in common wheat. Theor. Appl. Genet. 125: 967-973.

Gupta, P. K., Langridge, P., and Mir, R. R. 2010. Marker-assisted wheat breeding: Present status and future possibilities. Mol. Breed. 26:145-161

Hu, T. Z., Li, H. J., Liu, Z. J., Xie, C. J., Zhou, Y. L., Duan, X. Y., Jia, X., You, M. S., Yang, Z. M., Sun, Q. X., and Liu, Z. Y. 2008. Identification and molecular mapping of the powdery mildew resistance gene in wheat cultivar Yumai 66. Acta Agron. Sin. 34:545-550.

Huang, J., Zhao, Z. H., Song, F. J., Wang, X. M., Xu, H. X., An, D. G., and Li, H. J. 2012. Molecular detection of a gene effective against powdery mildew in wheat cultivar Liangxing66. Mol. Breed. 30:1737-1745.

Kassa, M. T., You, F. M., Fetch, T. G., Fobert, P., Sharpe, A., Pozniak, C. J., Menzies, J. G., Jordan, M. C., Humphreys, G., Zhu, T. T., Luo, M. C., McCartney, C. A., and Hiebert, C. W. 2016. Genetic mapping of SrCad and SNP marker development for marker-assisted selection of Ug99 stem rust resistance in wheat. Theor. Appl. Genet. 129:1373-1382.

Kosambi, D. D. 1943. The estimation of map distance from recombination values. Ann. Eugen. 12:172-175.

Li, B. N., Cao, X. R., Chen, L., Zhou, Y. L., Duan, X. Y., Luo, Y., Fitt, B. D. L., Xu, X. M., Song, Y. L., Wang, B. T., and Cao, S. Q. 2013. Application of geographic information systems to identify the oversummering regions of Blumeria graminis f. sp. tritici in China. Plant Dis. 97:1168-1174.

Li, H. J., Wang, X. M., Song, F. J., Wu, C. P., Wu, X. F., Zhang, N., Zhou, Y., and Zhang, X. Y. 2011. Response to powdery mildew and detection of resistance genes in wheat cultivars from China. Acta Agron. Sin. 37:943-954.

Li, L., Shi, X., Zheng, F., Li, C. C., Wu, D., Bai, G. H., Gao, D. R., Wu, J. C., and $\mathrm{Li}, \mathrm{T}$. 2016. A novel nitrogen-dependent gene associates with the lesion mimic trait in wheat. Theor. Appl. Genet. 129:2075-2084.

Lincoln, S., Daly, M., and Lander, E. 1993. Constructing Genetic Maps with Mapmaker/EXP30. Whitehead Institute Technical Report, 3rd ed. Whitehead Institute, Cambridge, MA.

Liu, C. L., Zhou, Q., Dong, L., Wang, H., Liu, F., Weng, J. F., Li, X. H., and Xie, C. X. 2016. Genetic architecture of the maize kernel row number revealed by combining QTL mapping using a high-density genetic map and bulked segregant RNA sequencing. BMC Genomics 17:915.

Lu, Y. Q., Wu, X. Y., Yao, M. M., Zhang, J. P., Liu, W. H., Yang, X. M., Li, X. Q., Du, J., Gao, A. N., and Li, L. H. 2015. Genetic mapping of a putative Agropyron cristatum-derived powdery mildew resistance gene by a combination of bulked segregant analysis and single nucleotide polymorphism array. Mol. Breed. 35:96.

Ma, H. Q., Kong, Z. X., Fu, B. S., Li, N., Zhang, L. X., Jia, H. Y., and Ma, Z. Q. 2011. Identification and mapping of a new powdery mildew resistance gene on chromosome 6D of common wheat. Theor. Appl. Genet. 123:1099-1106.

Ma, P. T., Xu, H. X., Li, L. H., Han, G. H., Luo, Q. L., Sun, Y., Xu, Y. F., Zhang, X. T., and An, D. G. 2016a. Characterization of a segregation distortion locus with powdery mildew resistance in a wheat-Thinopyrum intermedium introgression line. Plant Dis. 100:1541-1547.

Ma, P. T., Xu, H. X., Li, L. H., Zhang, H. X., Han, G. H., Xu, Y. F., Fu, X. Y., Zhang, X. T., and An, D. G. 2016b. Characterization of a new Pm2 allele conferring powdery mildew resistance in the wheat germplasm line FG-1. Front. Plant Sci. 7:546.
Ma, P. T., Xu, H. X., Luo, Q. L., Qie, Y. M., Zhou, Y. L., Xu, Y. F., Han, H. M., Li, L. H., and An, D. G. 2014. Inheritance and genetic mapping of a gene for seedling resistance to powdery mildew in wheat line X3986-2. Euphytica 200:149-157.

Ma, P. T., Xu, H. X., Xu, Y. F., Li, L. H., Qie, Y. M., Luo, Q. L., Zhang, X. T., Li, X. Q., Zhou, Y. L., and An, D. G. 2015a. Molecular mapping of a new powdery mildew resistance gene Pm2b in Chinese breeding line KM2939. Theor. Appl. Genet. 128:613-622.

Ma, P. T., Xu, H. X., Zhang, H. X., Li, L. H., Xu, Y. F., Zhang, X. T., and An, D. G. 2015b. The gene PmWFJ is a new member of the complex Pm2 locus conferring unique powdery mildew resistance in wheat breeding line Wanfengjian 34 . Mol. Breed. 35:210.

Ma, P. T., Zhang, H. X., Xu, H. X., Xu, Y. F., Cao, Y. W., Zhang, X. T., and An, D. G. 2015c. The gene $P m Y B$ confers broad-spectrum powdery mildew resistance in the multi-allelic $P m 2$ chromosome region of the Chinese wheat cultivar YingBo 700. Mol. Breed. 35:124.

McIntosh, R. A., Dubcovsky, J., Rogers, W. J., Morris, C., Appels, R., and Xia, X. C. 2016. Catalogue of gene symbols for wheat: 2015-2016 supplement. Online publication. https://shigen.nig.ac.jp/wheat/komugi/genes/symbolClassList.jsp

Mora, F., Castillo, D., Lado, B., Matus, I., Poland, J., Belzile, F., von Zitzewitz, J., and del Pozo, A. 2015. Genome-wide association mapping of agronomic traits and carbon isotope discrimination in a worldwide germplasm collection of spring wheat using SNP markers. Mol. Breed. 35:69.

Morgounov, A., Tufan, H. A., Sharma, R., Akin, B., Bagci, A., Braun, H. J., Kaya, Y., Keser, M., Payne, T. S., Sonder, K., and McIntosh, R. 2012. Global incidence of wheat rusts and powdery mildew during 1969-2010 and durability of resistance of winter wheat variety Bezostaya 1. Eur. J. Plant Pathol. 132: 323-340.

Pugsley, A. T., and Carter, M. V. 1953. The resistance of twelve varieties of Triticum vulgare to Erysiphe graminis tritici. Aust. J. Biol. Sci. 6:335-346.

Qiu, Y. C., Sun, X. L., Zhou, R. H., Kong, X. Y., Zhang, S. S., and Jia, J. Z. 2006. Identification of microsatellite markers linked to powdery mildew resistance gene Pm2 in wheat. Cereal Res. Commun. 34:1267-1273.

Ramirez-Gonzalez, R. H., Segovia, V., Bird, N., Fenwick, P., Holdgate, S., Berry, S., Jack, P., Caccamo, M., and Uauy, C. 2015. RNA-Seq bulked segregant analysis enables the identification of high-resolution genetic markers for breeding in hexaploid wheat. Plant Biotechnol. J. 13:613-624.

Rasheed, A., Wen, W., Gao, F. M., Zhai, S. N., Jin, H., Liu, J. D., Guo, Q., Zhang, Y. J., Dreisigacker, S., Xia, X. C., and He, Z. H. 2016. Development and validation of KASP assays for genes underpinning key economic traits in bread wheat. Theor. Appl. Genet. 129:1843-1860.

Ren, T. H., Chen, F., Zhang, H. Q., Yan, B. J., and Ren, Z. L. 2011. Genetic suppression of the powdery mildew resistance gene $P m 21$ in common wheat. Acta Phytopathol. Sin. 42:57-64.

Saghai-Maroof, M. A., Soliman, K. M., Jorgensen, R. A., and Allard, R. W. 1984. Ribosomal DNA spacer-length polymorphisms in barley: Mendelian inheritance, chromosomal location, and population dynamics. Proc. Natl. Acad. Sci. USA 81: 8014-8018.

Sánchez-Martín, J., Steuernage, B., Ghosh, S., Herren, G., Hurni, S., Adamski, N., Vrána, J., Kubaláková, M., Krattinger, S. G., Wicker, T., Doležel, J., Keller, B., and Wulff, B. B. H. 2016. Rapid gene isolation in barley and wheat by mutant chromosome sequencing. Genome Biol. 17:221

Selter, T. D., Shatalina, M., Singla, J., and Keller, B. 2014. Identification and implementation of resistance: Genomics-assisted use of genetic resources for breeding against powdery mildew and Stagonospora nodorum blotch in wheat. Pages 359-383 in: Genomics of Plant Genetic Resources, Vol. 2. R. Tuberosa, A. Graner, and E. Frison, eds. Springer, Dordrecht, Netherlands.

Sheng, B. Q., and Duan, X. Y. 1991. Improvement of scale 0-9 method for scoring adult plant resistance to powdery mildew of wheat. Beijing Agric. Sci. 1:38-39.

Shi, Y. Q., Wang, B. T., Li, Q., Wu, X. Y., Wang, F., Liu, H., Tian, Y. E., and Liu, Q. R. 2009. Analysis of the virulent genes of Erysiphe graminis f. sp. tritici and the resistance genes of wheat commercial cultivars in Shaanxi Province. J. Triticeae Crops 29:706-711

Si, Q. M., Zhang, X. X., Duan, X. Y., Sheng, B. Q., and Zhou, Y. L. 1992. On gene analysis and classification of powdery mildew (Erysiphe graminis f. sp. tritici) resistant wheat varieties. Acta Phytopathol. Sin. 22:349-355.

Song, W., Sun, H. G., Sun, Y. L., Zhao, Z. H., Wang, X. O., Wu, X. F., and Li, H. J. 2014. Chromosomal localization of the gene for resistance to powdery mildew in the wheat cultivar Wennong14. Acta Agron. Sin. 40:798-804.

Summers, R. W., and Brown, J. K. M. 2013. Constraints on breeding for disease resistance in commercially competitive wheat cultivars. Plant Pathol. 62: $115-121$.

Sun, H. G., Song, W., Sun, Y. L., Chen, X. M., Liu, J. J., Zou, J. W., Wang, X. M., Zhou, Y. F., Lin, X. H., and Li, H. J. 2015. Resistance of 'Zhongmai 155' wheat to powdery mildew: Effectiveness and detection of the resistance gene. Crop Sci. 55:1017-1025

Sun, Y. L., Zou, J. W., Sun, H. G., Song, W., Wang, X. M., and Li, H. J. 2015 PmLX66 and PmW14: New alleles of $P m 2$ for resistance to powdery mildew in the Chinese winter wheat cultivars Liangxing 66 and Wennong 14. Plant Dis. 99:1118-1124.

Trick, M., Adamski, N. M., Mugford, S. G., Jiang, C. C., Febrer, M., and Cristobal Uauy, C. 2012. Combining SNP discovery from next-generation sequencing 
data with bulked segregant analysis (BSA) to fine-map genes in polyploid wheat. BMC Plant Biol. 12:14.

Xu, H. X., Yi, Y. J., Ma, P. T., Qie, Y. M., Fu, X. Y., Xu, Y. F., Zhang, X. T., and An, D. G. 2015. Molecular tagging of a new broad-spectrum powdery mildew resistance allele $P m 2 c$ in Chinese wheat landrace Niaomai. Theor. Appl. Genet. 128:2077-2084.

Xu, W. G., Li, C. X., Hu, L., Wang, H. W., Dong, H. B., Zhang, J. Z., and Zan, X. C. 2011. Identification and molecular mapping PmHNK54: A novel powdery mildew resistance gene in common wheat. Plant Breed. 130:603-607.

Xu, Y. F., Wang, R. F., Tong, Y. P., Zhao, H. T., Xie, Q. G., Liu, D. C., Zhang, A. M., Li, B., Xu, H. X., and An, D. G. 2014. Mapping QTLs for yield and nitrogen-related traits in wheat: Influence of nitrogen and phosphorus fertilization on QTL expression. Theor. Appl. Genet. 127:59-72.
Yin, G. H., Li, G. Y., He, Z. H., Liu, J. J., Wang, H., and Xia, X. C. 2009. Molecular mapping of powdery mildew resistance gene in wheat cultivar Jimai 22. Acta Agron. Sin. 35:1425-1431.

Zhang, R. Q., Sun, B. X., Chen, J., Cao, A. Z., Xing, L. P., Feng, Y. G., Lan, C. X. and Chen, P. D. 2016. Pm55, a developmental-stage and tissue-specific powdery mildew resistance gene introgressed from Dasypyrum villosum into common wheat. Theor. Appl. Genet. 129:1975-1984.

Zhao, Z. H., Sun, H. G., Song, W., Lu, M., Huang, J., Wu, L. F., Wang, X. M., and Li, H. J. 2013. Genetic analysis and detection of the gene MlLX99 on chromosome $2 \mathrm{BL}$ conferring resistance to powdery mildew in the wheat cultivar Liangxing 99. Theor. Appl. Genet. 126:3081-3089.

Zhou, M.-G., and Jia, X.-J. 2015. Wheat pathogens in China. Pages 313-328 in: Fungicide Resistance in Plant Pathogens. H. Ishii and D. W. Hollomon, eds Springer, Tokyo, Japan. 